\title{
German Recommendations for Diagnosis and Treatment of Breast Cancer 2008. What is New from the Breast Commission of the German Gynaecological Oncology Working Group (AGO)?
}

\author{
Eva J. Kantelhardt Christoph Thomssen on behalf of the breast commission in the working \\ group Gynaecological Oncology (AGO)*
}

Universitätsfrauenklinik der Martin-Luther-Universität Halle-Wittenberg, Halle (Saale), Germany

\section{Key Words}

Breast cancer - Diagnostics - Treatment - Recommendations

\section{Summary}

Some form of standardised treatment for patients with breast cancer is probably well established in German health institutions throughout the country. Keeping standards up to date, however, is a rather complex activity involving time and financial resources. Turnover of scientific knowledge is fast and numerous. Most health care professionals will not be able to ensure such kind of evidence-based diagnostics and treatment standards of care alone. The breast commission of the German Gynaecological Oncology Working Group (Arbeitsgemeinschaft Gynäkologische Onkologie, AGO) has again published their yearly update on recommendations for the diagnosis and therapy of breast cancer. Literature was screened for new findings up to the beginning of 2008. Changes were incorporated in nearly all of the 25 chapters. Notably, duration and schedules of adjuvant endocrine therapy, updated adjuvant chemotherapy regimens, findings in plastic surgery, radiotherapy for node positive disease, evaluation of new prognostic and predictive factors, classification of lobular neoplasia, treatment of Paget's disease, inflammatory breast cancer, and sarcoma, as well as lapatinib and bevacizumab are discussed, only to mention a few. Using this easy accessible tool, high quality care can be given to the patient, standards can be communicated and justified to the health care system and new ideas will arise for clinical and pre-clinical development.

\author{
Schlüsselwörter \\ Mammakarzinom - Diagnostik · Therapie - Empfehlungen
}

\begin{abstract}
Zusammenfassung
In den meisten deutschen Gesundheitseinrichtungen gibt es einen Standard der Behandlung von Patientinnen mit Mammakarzinom. Diese Standards auf dem neuesten Stand zu halten, ist allerdings eine sehr aufwendige Angelegenheit. Zeit und finanzielle Ressourcen sind erforderlich. Der Umsatz wissenschaftlicher Erkenntnis ist vielfältig und schnell. Den meisten Medizinern wird es nicht möglich sein, alleine solche Art evidenzbasierter Diagnostik- und Therapie-Standards zu gewährleisten. Die Kommission Mamma der Arbeitsgemeinschaft Gynäkologische Onkologie (AGO) hat erneut die jährliche Aktualisierung der Empfehlungen zu Diagnostik und Therapie des Mammakarzinoms veröffentlicht. Die Literatur wurde bis Anfang 2008 recherchiert. Änderungen wurden in fast allen 25 Kapiteln vorgenommen. Dauer und Schema adjuvanter endokriner Therapie, neue Protokolle adjuvanter Chemotherapie, Ergebnisse plastischer Chirurgie, Bestrahlung nodal-positiver Patientinnen, Bewertung neuer prognostischer und prädiktiver Faktoren, Klassifikation lobulärer Neoplasie, Behandlung von Morbus Paget, inflammatorischem Mammakarzinom und Sarkom sowie Lapatinib und Bevacizumab werden diskutiert, um nur einige Themen zu nennen. Durch Nutzung dieses einfach zugänglichen Werkzeugs ist eine hochqualifizierte Versorgung der Patientinnen möglich, Standards können diskutiert werden, und neue Ideen zur klinischen und präklinischen Entwicklung werden entstehen.
\end{abstract}

*Co-Authors (members of the 'AGO Kommission Mamma'): Ute-Susan Albert, Marburg; Ingo Bauerfeind, München; Joachim Bischoff, Magdeburg; Jens Uwe Blohmer, Berlin; Klaus Brunnert, Osnabrück; Serban D. Costa, Magdeburg;Peter Dall, Lüneburg; Ingo J. Diel, Mannheim; Nikos Fersis, Heidelberg; Michael Friedrich, Lübeck; Kay Friedrichs, Hamburg; Bernd Gerber, Rostock; Uwe-Jochen Göhring, Bonn; Volker Hanf, Fürth; Nadia Harbeck, München; Jens Huober, St. Gallen; Christian Jackisch, Offenbach; Wolfgang Janni, München; Walter Jonat, Kiel (DKH); Manfred Kaufmann, Frankfurt; H. Kreipe, Hannover (DGP); Hans-Joachim Lück, Wiesbaden; Nicolai Maass, Kiel; Volker Möbus, Volkmar Müller, Hamburg; Frankfurt; Ulrike Nitz, Mönchengladbach; Carsten Oberhoff, Essen; Mahdi Rezai, Düsseldorf; Gerhard Schaller, Berlin; Anton Scharl, Amberg; Rita Schmutzler, Köln; Andreas Schneeweiß, Heidelberg (AIO); Ingrid Schreer, Kiel (DGS); Florian Schütz, Heidelberg; Peter Sinn, Heidelberg (Pathologie); Erich F. Solomayer, Tübingen; Rainer Souchon, Hagen (ARO); Elmar Stickeler, Freiburg; Christoph Thomssen, Halle (Sprecher der AGO Kommission Mamma); Michael Untch, Berlin; Gunter von Minckwitz, Neu-Isenburg/ Frankfurt

\begin{tabular}{ll}
\hline KARGER & @ 2008 S. Karger GmbH, Freiburg \\
Fax +49 7614520714 & Accessible online at: \\
$\begin{array}{l}\text { E-mail Information@Karger.de } \\
\text { www.karger.com }\end{array}$ & www.karger.com/brc
\end{tabular}

Dr. med. Eva J. Kantelhardt

Universitätsfrauenklinik der Martin-Luther-Universität Halle-Wittenberg Ernst-Grube-Str. 40,

06120 Halle (Saale), Germany

Tel. +49 345557-1847, Fax -1501

E-mail eva.kantelhardt@medizin.uni-halle.de 


\section{Introduction}

Treating breast cancer patients every day leads to the development of a certain routine. Most women are in their 50s, hopefully they arrive early, and the impact of operation, chemotherapy, hormonal therapy, radiotherapy, and possibly trastuzumab is on our mind. Why bother about up-to-date standards of care when everything is clear? Do we need any further information except for those patients with unusual presentation? Often, we start to search the literature only when we are at our wits' end. And we find it a rather timeconsuming activity!

Improving the quality of individual care for all patients is the main goal of the guidelines set by the German Gynaecological Oncology Working Group (Arbeitsgemeinschaft Gynäkologische Onkologie, AGO). The idea is to give advice not only on rare cases but also for every-day patients. Individualised suggestions concerning diagnostics and treatment shall be guaranteed. Evidence-based decisions shall be the basis of all discussions with patients, relatives, and colleagues. Economic considerations have to be increasingly included in the decision making process. Guidelines can contribute to saving public resources. On the other hand, greater expenses can be justified to the health care provider if they are recommended in guidelines. Guidelines also improve the knowledge transfer from research to clinical practice. Furthermore, open questions are clearly outlined, thus giving directions for future clinical research.

The AGO breast commission updated the AGO recommendations for diagnostics and therapy of breast cancer in January 2008 for the 7th time [1]. These wide-spread recommendations are arranged in 25 chapters of 10-15 slides each with brief and clear evidence-based statements. This year, special attention was given to the references. All topics were edited by members of the commission. The data bases evaluated were Pubmed, ASCO, SABCS, ECCO, EBCC, COCHRANE, among others. Publications of the last 5 years were screened systematically. In addition, the following existing guidelines were evaluated: St. Gallen Consensus for adjuvant therapy of breast cancer [2], American Association of Clinical Oncology [3], and National Comprehensive Cancer Network [4]. The AGO breast commission tries to provide the recommendations in an independent and transparent way. All topics were discussed in the plenum and agreed on; consensus or a predominant majority was aimed for. The authors of the chapters rotated nearly each year. The guidelines 2008 were presented to the public in January 2008 and discussed thoroughly. All conflicts of interest possibly resulting from co-operation and connections with the industry were disclosed. Members of the AGO commission are not only gynaecologists but also colleagues from the fields of radiology, pathology, radiotherapy and internal medicine. The requirements for a membership are clear, and all present members have to undergo the corresponding scoring process in regular intervals.
Table 1. AGO grades of recommendation, from Kommission 'Mamma' der Arbeitsgemeinschaft für Gynäkologische Onkologie e.V. (AGO) Guidelines 2008, version 1.1; www.ago-online.de

++ This investigation or therapeutic intervention is highly beneficial for patients, can be recommended without restriction, and should be performed.

$+\quad$ This investigation or therapeutic intervention is of limited benefit for patients and can be performed.

+/- This investigation or therapeutic intervention has not shown benefit for patients and may be performed only in individual cases.

According to current knowledge, a general recommendation cannot be given.

- This investigation or therapeutic intervention can be of disadvantage for patients and might not be performed.

-/ This investigation or therapeutic intervention is of clear disadvantage for patients and should be avoided or omitted in any case.

Evaluation of evidence was done using the Oxford Levels of Evidence (LoE) [5]. Additionally, the AGO committee members intentionally gave subjective clinically orientated recommendations to each individual guideline statement (table 1). A detailed presentation of the guidelines as a text version appeared at the end of 2007 [6]. Being concisely up to date, the AGO recommendations have obtained their own relevance next to the S3 guideline 'Breast Cancer' of the German Cancer Society (Deutsche Krebsgesellschaft e. V.) [7]. Besides, they are an indispensable basis and preparation for the production of the $\mathrm{S} 3$ guideline. The most important new aspects of the AGO recommendations 2008 are presented in this report.

\section{Important New Aspects of the AGO Recommendations 2008}

\section{Early Detection and Diagnosis}

If clinical examination, mammography, and ultrasound are not conclusive, morphological diagnosis based on biopsy material is warranted, as magnetic resonance imaging (MRI) has a high sensitivity but too low a specificity to allow definitive diagnosis and is therefore not recommended for diagnosis (LoE 1cA, AGO +/-). Minimally invasive biopsy allows definitive diagnosis in most cases at reduced expenditure.

\section{Prognostic and Predictive Factors}

Interesting results show the importance of metabolism for the effect of tamoxifen [9]. A polymorphism in the gene of the enzyme Cyp2D6 could therefore possibly predict this effect (LoE 2b-B, AGO+/-). Prognostic factors are especially important in node-negative breast cancer (fig. 1). The use of computer-based software systems for estimation and visualisation of prognosis and therapeutic effects (e.g., adjuvantonline [8]) can be helpful (LoE $2 \mathrm{~b}(-)-\mathrm{D}, \mathrm{AGO}+)$. Gene expression profiles such as Oncotype DX ${ }^{\circledR}$ (Genomic Health, Inc., Redwood City, CA, USA) and Mammaprint ${ }^{\circledR}$ (Agendia, Amsterdam, the 


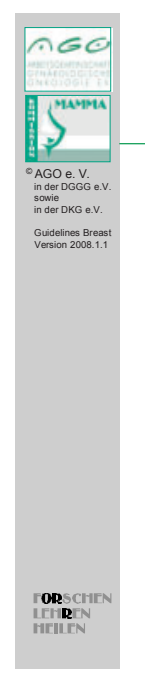

Prognostic Factors in Node-Negative Breast Cancer

Fig. 1. Prognostic factors in node-negative breast cancer, from Kommission 'Mamma' der Arbeitsgemeinschaft für Gynäkologische Onkologie e.V. (AGO) Guidelines 2008, version 1.1; www.ago-online.de.

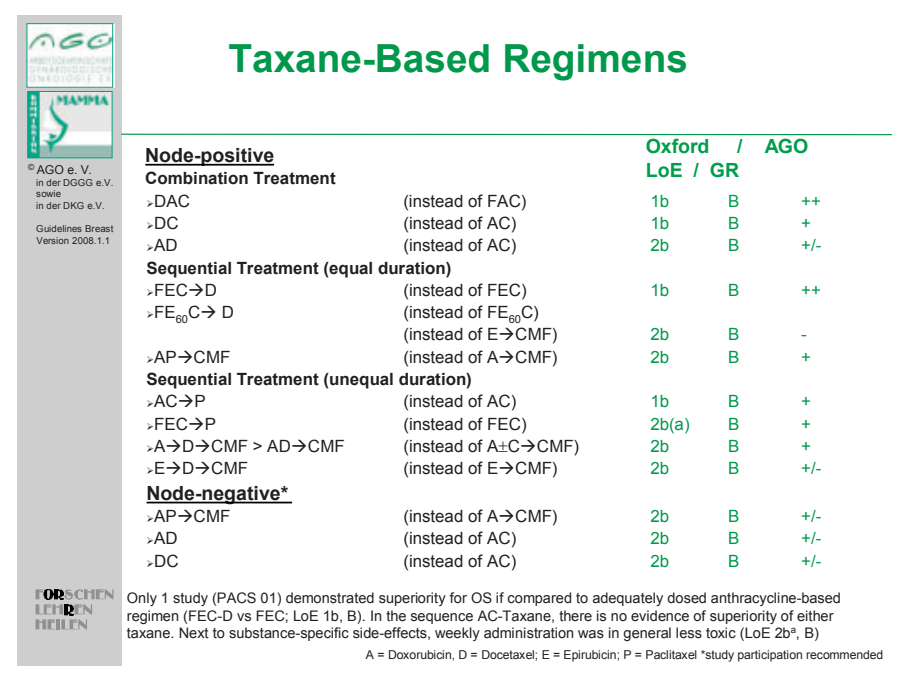

Fig. 3. Taxane-based regimens in adjuvant chemotherapy, from: Kommission 'Mamma' der Arbeitsgemeinschaft für gynäkologische Onkologie e.V. (AGO) Guidelines 2008, version 1.1; www.ago-online.de.

Netherlands) show interesting results for prognosis and prediction. However, a validation of these results is still due. Therefore, these tests are not recommended for routine use (LoE 2b-B, AGO-). Participation in one of the current studies is recommended.

\section{Adjuvant Endocrine Therapy in Premenopausal Patients}

In low-risk situations, tamoxifen alone is considered standard therapy (LoE 1a-A, AGO++). The combination of gonadotropin-releasing hormone $(\mathrm{GnRH})$ analogues plus tamoxifen can be discussed ( $\mathrm{LoE} 1 \mathrm{~b}-\mathrm{B}, \mathrm{AGO}+$ ); therapy-induced morbidity, however, should then be considered (low risk!). Standard adjuvant chemo-endocrine therapy (in highand intermediate-risk situations) is the sequence of chemo-

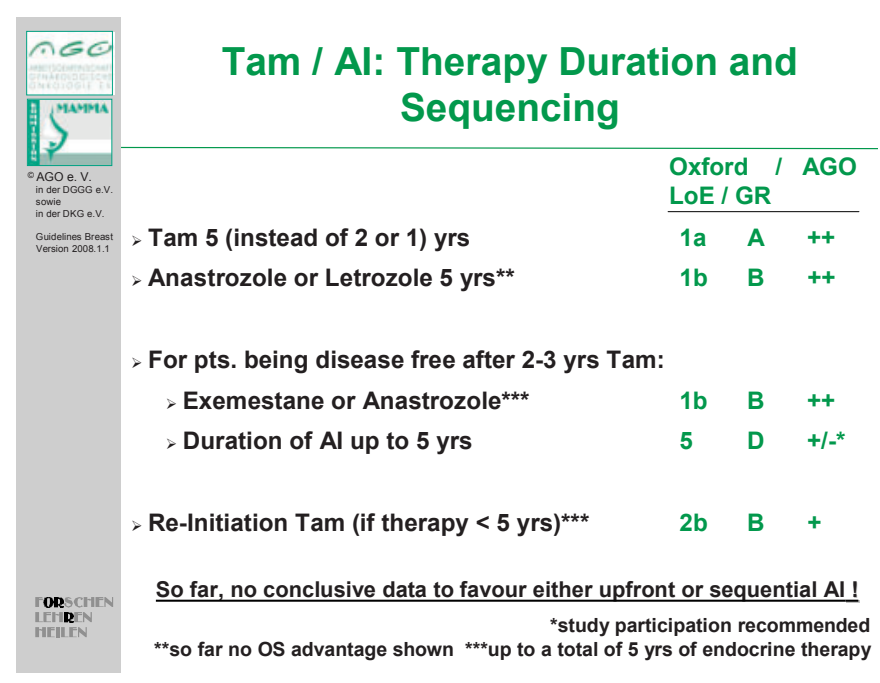

Fig. 2. Tamoxifen/aromatase inhibitor: therapy duration and sequencing, from Kommission 'Mamma' der Arbeitsgemeinschaft für gynäkologische Onkologie e.V. (AGO) Guidelines 2008, version 1.1; www.ago-online.de.

therapy followed by 5 years of tamoxifen (LoE 1a-A, $\mathrm{AGO}++$ ). In young patients (under 40 years), additional ovarian suppression can be useful ( $\mathrm{LoE} 2 \mathrm{a}-\mathrm{C}, \mathrm{AGO}+)$, study participation is recommended.

\section{Adjuvant Endocrine Therapy in Postmenopausal Patients}

Tamoxifen for 5 years remains the unchanged 'good standard' (LoE 1a-A, AGO++). Most postmenopausal patients might nevertheless profit from an adjuvant therapy with aromatase inhibitors - either upfront or in sequence to tamoxifen (LoE1b-A, AGO++). Long-term data of the ATAC study [10] and the BIG study [11] show that primary aromatase inhibitor therapy and primary tamoxifen therapy can be considered as equal $(\mathrm{AGO}++)$. It has to be stated that, so far, there are no conclusive data in favour of either upfront therapy or sequential therapy with aromatase inhibitors (fig. 2).

\section{Adjuvant Chemotherapy and Trastuzumab Therapy}

Anthracycline-based chemotherapy in triple combination (e.g. 5-fluorouracil, epirubicin, cyclophosphamide (FEC), 5-fluorouracil, doxorubicin, cyclophosphamide (FAC)) is regarded as standard chemotherapy. For node-positive tumours, additional use of taxane-containing regimens is recommended. Within taxane-containing regimens, FEC-docetaxel and docetaxel, doxorubucin, cyclosphosphamide are still clearly recommended (LoE 1b-B, AGO++). Further regimens are shown in figure 3. Concerning survival, anthracycline-free therapy with docetaxel/cyclophos-phamide is superior to the combination therapy doxorubicin and cyclophosphamide (AC) and can be recommended in individual cases ( $\mathrm{LoE} 1 \mathrm{bB}, \mathrm{AGO}+$ ). For node-positive breast cancer, the use of dose-dense (dd) chemotherapy is to be considered. Besides the AGO pattern dd(E-P-C) q2w, the American patterns dd(A-C-P)/dd(AC-P) 
q2w (both with G-CSF support) and AC-ddP q1w $\times 12($ LoE 1b-B, AGO+) are also applicable. Contributing to more clarification, it is separately mentioned that adjuvant trastuzumab therapy can be given at the same time with radiotherapy (LoE $2 \mathrm{~b}-\mathrm{B}, \mathrm{AGO}+$ ). The application of trastuzumab parallel to epirubicin must be limited to trials in the adjuvant and likewise in the metastatic situations ( $\mathrm{LoE} 2 \mathrm{~b}-\mathrm{B}, \mathrm{AGO}+/-$ ).

\section{Supportive Care}

Dexrazoxane is recommended as antidote for anthracycline extravasations. Using anthracycline-containing therapy in patients with cardiac risk factors, dexrazoxane can be used for cardiac protection (LoE 2b-B, AGO+); however, alternative regimens (anthracycline-free therapy or administration of liposomal anthracycline) should be considered (LoE 5-D, $\mathrm{AGO}++)$. The use of anaemia prophylaxis by means of erythropoietin preparations does not improve prognosis. On the contrary, possible disadvantages must be taken into account. Primary prophylaxis for standard chemotherapy is therefore not indicated.

\section{Therapy Side Effects}

Risk factors for anthracycline- or trastuzumab-induced cardiotoxicitiy are age ( $>65$ years), obesity (body mass index $>27 \mathrm{~kg} / \mathrm{m}^{2}$ ), uncontrolled hypertension, hypercholesterolemia, diabetes mellitus, and pre-existing cardiac disease (including borderline left ventricular ejection fraction, LVEF). Radiotherapy of the chest wall is not considered as a risk factor any longer (LoE 2b-B).

\section{Breast Cancer Surgery - Oncological Aspects}

The surgical trauma should be minimised by sentinel lymph node procedures whenever possible. The diagnostic processing of the sentinel lymph node by means of reverse transcription polymerase chain reaction (RT-PCR) is not sufficiently validated and is not to be used (LoE 4-D, AGO-). Sentinel node excision (SNE) is not indicated in prophylactic bilateral or contralateral mastectomy (LoE 3b-B, AGO-/-). For perioperative staging for high metastatic potential, fluorodeoxyglucose-positron emission tomography (FDG-PET) or FDGPET computed tomography $(\mathrm{CT})$ are not recommended (LoE 2a-B, AGO-).

\section{Plastic Reconstructive Aspects after Mastectomy}

A large retrospective analysis of implant reconstruction [13] modifies the past rejection of using implants after radiotherapy of the chest wall. In principle, the implant supply is considered a possible method of reconstruction ( $\mathrm{LoE} 2 \mathrm{a}-\mathrm{B}$; $\mathrm{AGO}+$ ). Implant reconstruction without radiotherapy is very feasible $(\mathrm{LoE} 2 \mathrm{a}-\mathrm{B}, \mathrm{AGO}++)$. Due to current data, there is no longer a clear preference to the order of timing implant reconstruction and radiotherapy (implant supply before or after radiotherapy: LoE 2a-B, AGO+/-). Breast reconstruction by means of transrectus abdominis muscle (TRAM) flap is generally possi- ble by pedicled or free techniques ( $\mathrm{LoE} 3 \mathrm{~b}-\mathrm{C}, \mathrm{AGO}+$ ). When using free tissue transfer techniques, free TRAM, DIEP (deep inferior epigastric artery perforator) or SGAP (superior gluteal artery perforator) / IGAP (inferior gluteal artery perforator) flaps are recommended.

\section{Adjuvant Radiotherapy}

Radiotherapy of the locoregional lymph node areas has received special consideration for the first time. Irradiation of the supraclavicular region (supra clavicular groove (SCG) field) is recommend in the case of infestation of more than 9 axillary lymph nodes ( $\mathrm{LoE} 3 \mathrm{a}-\mathrm{B}, \mathrm{AGO}++$ ), involvement of level 3 lymph nodes (LoE 3b-B, AGO+), and insufficient axillary dissection (e.g., when only level 1 is dissected despite axillary lymph node involvement). Also, the SCG field should be included when the indication for axillary irradiation is given for other reasons. Irradiation of the internal mammary region is not recommended ( $\mathrm{LoE} 4-\mathrm{D}, \mathrm{AGO}-$ ). The indication for adjuvant radiotherapy after mastectomy is given regardless of systemic therapy (LoE 1a-A, AGO++). New data revealed that the indication for irradiation of the chest wall after mastectomy is likewise favourable when less than 4 axillary lymph nodes are involved. The absolute benefit might, however, be small in older patients (LoE 1a-A, AGO+).

\section{Pathology}

Emphasis is put on the standardisation of procedures, quality assurance, and central reviewing especially for HER2 testing. Discordant findings in core biopsy and open biopsy need a second opinion.

\section{Breast Cancer Follow-Up}

Unchanged clinical examination is advised as standard care during follow-up. Elaborate machine-aided diagnostics including PET or whole body MRI are not recommended (LoE 2b$\mathrm{B}, \mathrm{AGO}-$ ).

\section{Complementary Therapy and Hormonal Treatment}

The main topic of this chapter is the treatment of postmenopausal symptoms such as hot flushes. When the patient is on tamoxifen, venlaflaxin (serotonin-norepinephrine reuptake inhibitor, SNRI) should be used as co-medication to minimise interference due to substances interacting with the tamoxifen metabolism (LoE 1b-B, AGO+). Paroxetine and fluoxetine could possibly lead to a loss of the tamoxifen effect. Apart from medical treatment, regular exercise can favourably affect postmenopausal hot flushes ( $\mathrm{LoE} 2 \mathrm{~b}-\mathrm{D}, \mathrm{AGO}+$ ).

\section{Precursor Lesions}

The definition of lobular neoplasia (LN) was introduced in place of lobular carcinoma in situ (LCIS). Pleomorphic LCIS (LN 3) is emphasised as a special lesion which should be treated like ductal carcinoma in situ (DCIS). The treatment of LN has been re-arranged: i) LN in needle biopsy (core nee- 


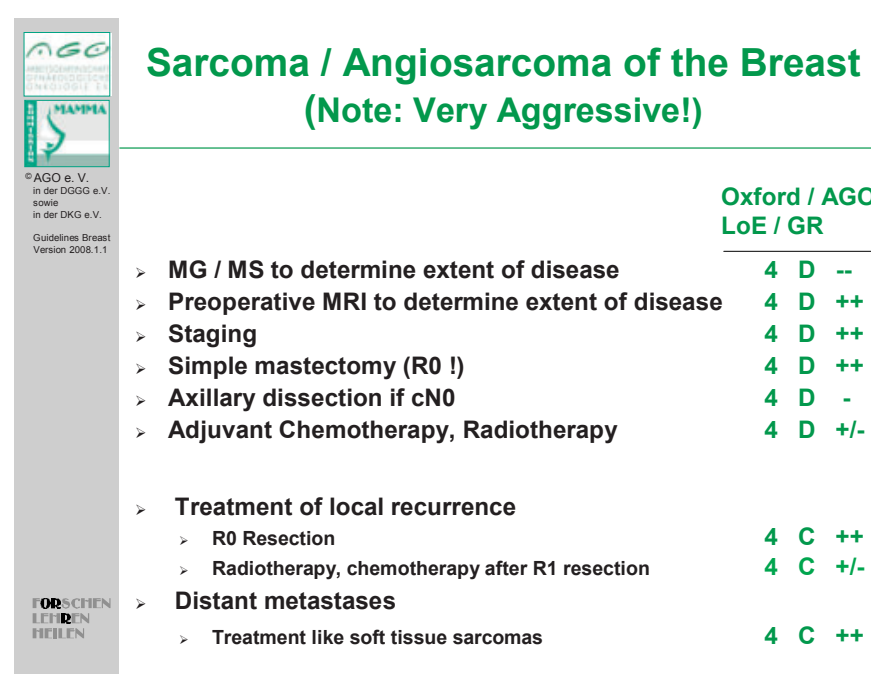

Fig. 4. Treatment of sarcoma, from: Kommission 'Mamma' der Arbeitsgemeinschaft für gynäkologische Onkologie e.V. (AGO) Guidelines 2008, version $1.1 ;$ www.ago-online.de

dle/VAB) with mammographically suspicious lesions must always be clarified by open biopsy (LoE 4-C, AGO+); an exception is the low degree lesion (LN1) as an incidental finding; ii) $\mathrm{LN}$ in open biopsy is no longer recommended for re-operation independent of the resection margins ( $\mathrm{LoE} 4-\mathrm{C}, \mathrm{AGO}+$ ). In high degree lesions (LN 3), pleomorphic $\mathrm{LN}$, and mixed DCIS/LN lesions, the appropriate therapy is similar to DCIS; iii) when treating invasive breast cancer by breast conserving therapy, LN at the margins of the specimen do not need further resection; an exception is pleomorphic LN (LoE 5-D, $\mathrm{AGO}+$ ).

\section{Ductal Carcinoma Situ (DCIS)}

Up to now, there have been no conclusive data to state in which cases radiotherapy after breast conserving therapy for DCIS can be omitted. All patients benefit, but no influence on survival is seen. Patients with low grade DCIS $(<2 \mathrm{~cm}$, margins $>10 \mathrm{~mm}$ ) may only have a minor benefit so that radiotherapy may be avoided. Breast conserving therapy can be offered in multifocal DCIS when operated with appropriate care, good imaging, and histopathologic examination (postoperative radiotherapy is presumed; $\mathrm{LoE} 2 \mathrm{~b}-\mathrm{B} ; \mathrm{AGO}+$ ).

\section{Hereditary Breast Cancer}

The list of indications for testing for BRCA 1/2 mutation (probability $\geq 10 \%$ ) was extended due to the data of the German consortium. When having male breast cancer in the family, a diagnostic procedure is only recommended if at least a second breast or ovarian cancer is found in the family ( $\mathrm{LoE}$ 2b-B, AGO++). The discussion about giving chemotherapy with a platinum combination in BRCA 1/2-associated breast cancer is not finalised ( $\mathrm{LoE} 3-\mathrm{C}, \mathrm{AGO}+/-)$. Study participation is recommended.

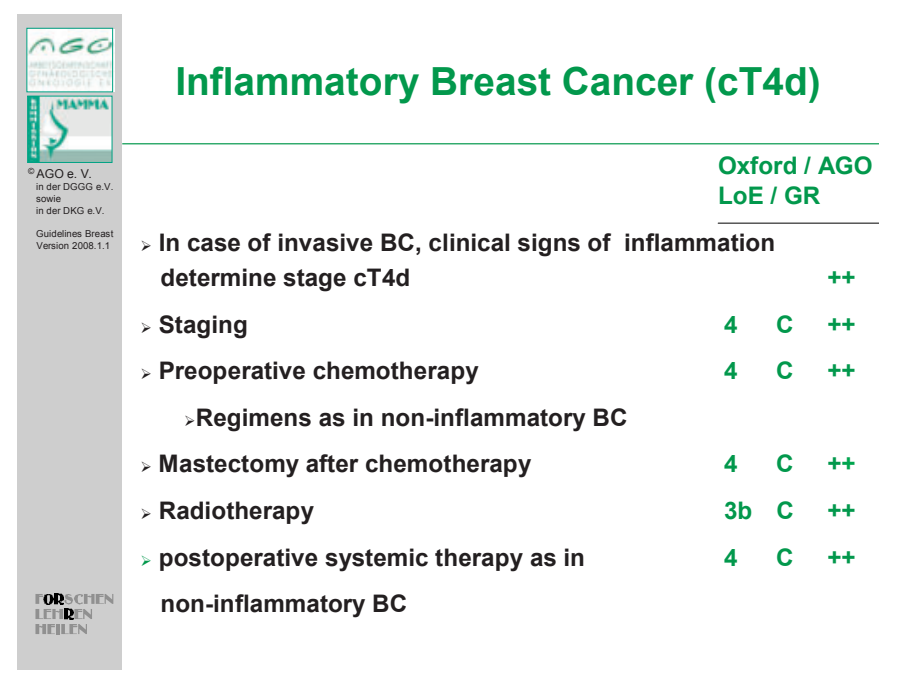

Fig. 5. Treatment of inflammarory breast cancer, from Kommission 'Mamma' der Arbeitsgemeinschaft für gynäkologische Onkologie e.V. (AGO) Guidelines 2008, version 1.1; www.ago-online.de.

\section{Breast Cancer in Specific Situations}

Breast cancer in pregnancy should not justify preterm delivery (before maturation of the child), since this does not improve the prognosis (LoE 4-C, AGO++). The mode of delivery is not to be modified because of the breast cancer ( $\mathrm{LoE} 4-\mathrm{C}$, AGO++), however, giving birth less than 3 weeks after the last chemotherapy should be avoided. When adjuvant chemotherapy is necessary after delivery, breast feeding may have to be stopped due to contraindications of the used substances. Pregnancy-associated breast cancer (diagnosis during and in the first year after pregnancy) should be entered into the national registry study of the German Breast Group.

When treating elderly patients with breast cancer ( $>70$ years), geriatric assessments should always be taken into account (LoE 2b-B, AGO++). Fit elderly patients with good life expectancy (> 5 years), good physical condition, and little comorbidity can be offered therapy according to the usual standard (as in 'younger' patients) ( $\mathrm{LoE} 2 \mathrm{a}-\mathrm{C}, \mathrm{AGO}++)$. Therapy for frail elderly patients must be adapted to the situation ( $\mathrm{LoE}$ 2b-C, AGO++): reduced surgical therapy, reduced radiotherapy, no adjuvant chemotherapy.

New recommendations concerning the treatment of sarcoma (fig. 4), inflammatory breast cancer (fig. 5), and Paget's disease of the breast were added. When suspecting Paget's disease of the breast, histological examination for suspicious nipple findings is obligatory, further diagnostics must exclude underlying invasive carcinoma or DCIS. The operation must always include the nipple and areola. When exclusively Paget's disease is found and operated with negative margins, no radiotherapy is required ( $\mathrm{LoE} 4-\mathrm{D}, \mathrm{AGO++})$.

\section{Locoregional Recurrence}

In the setting of operating locoregional recurrence with clini- 


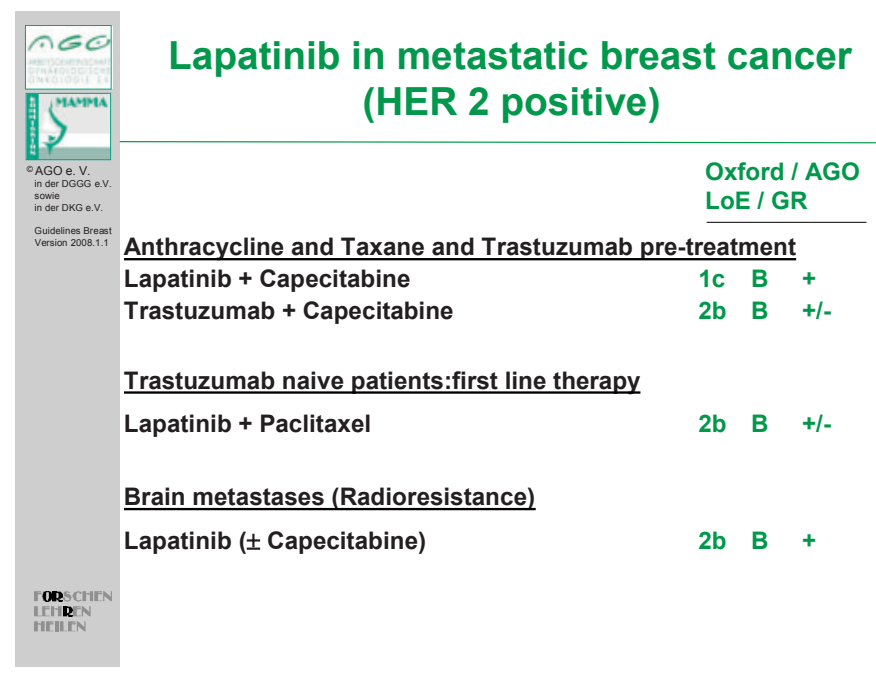

Fig. 6. Lapatinib in metastatic breast cancer, from Kommission 'Mamma' der Arbeitsgemeinschaft für gynäkologische Onkologie e.V. (AGO) Guidelines 2008, version 1.1; www.ago-online.de.

cally free axilla, primary axillary intervention is not recommended if done before. If SNE was done in the primary operation, it may be repeated ( $\mathrm{LoE} 4-\mathrm{D}, \mathrm{AGO}+-$ ).

\section{Endocrine Therapy of Metastatic Breast Cancer}

Since in particular the hormone receptor status can change during the course of the disease, it can be helpful to obtain a histology from metastatic sites (e.g., by needle biopsy).

\section{Cytotoxic Therapy in Metastatic Breast Cancer}

In addition to the known substances, nanoparticle-bound paclitaxel (nab paclitaxel) will be available in the future as an effective substance for first-line situations (also when pre-treated with anthracycline-based regimens) (LoE 2b-B, AGO+). When pre-treated with anthracyclines and taxanes, combinations of ixabepilone/capecitabine and gemcitabine/vinorelbin are also described as effective patterns. Due to the relatively high rate of neutropenia, these patterns should be used rather sparingly (LoE 2b-B, AGO+/-). Cytotoxic therapy in metastatic breast cancer can be continued as long as the 'therapeutic index' remains positive (advantages outweigh side effects). Therapy can be discontinued when reaching remission, or can be continuously given until progression ( $\mathrm{LoE} 2 \mathrm{~b}-\mathrm{B}, \mathrm{AGO}+$ ). In any case, one should not change therapy to alternative substances without progression ( $\operatorname{LoE} 2 \mathrm{~b}^{\mathrm{a}}-\mathrm{B}, \mathrm{AGO}-$ ).

\section{Specific Sites of Metastasis}

When bone marrow is involved and associated with pancytopenia (marrow infiltration), a consistent, well controllable chemotherapy must be applied. Besides weekly epirubicin application, weekly paclitaxel administration can also be considered (LoE 5-D, $\mathrm{AGO}++$ ).

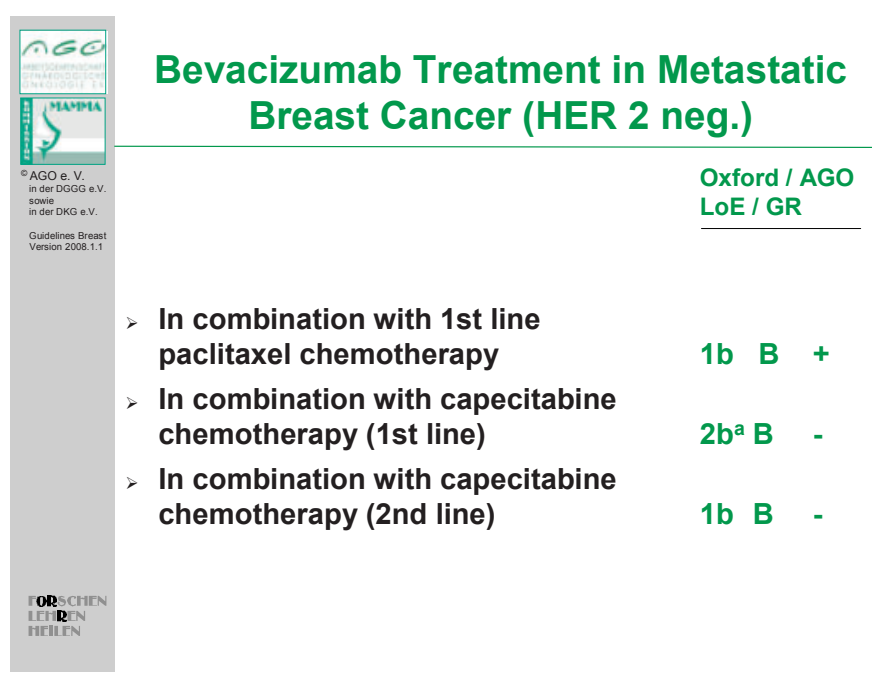

Fig. 7. Bevacizumab treatment in metastatic breast cancer, from Kommission 'Mamma' der Arbeitsgemeinschaft für gynäkologische Onkologie e.V. (AGO) Guidelines 2008, version 1.1; www.ago-online.de.

\section{Bone Metastases}

The recommendations regarding the treatment of bone metastases remain unchanged in general. The special elaboration of the topic 'therapy-induced bone mineral loss' is new. The repeated measurement of the bone density appears nowadays recommendable, as soon as therapies with risks for bone mineral loss are started, e.g., aromatase inhibitors, GnRH analogues (LoE 2b-B, AGO+). Treatment with bisphosphonates is indicated in osteopenia or osteoporosis (LoE 1b-B, AGO+). Analogous to other situations (corticosteroid-induced osteoporosis), it can be concluded that regular exercise, calcium and vitamin $\mathrm{D}$ substitution, and adequate body weight (body mass index $>18 \mathrm{~kg} / \mathrm{m}^{2}$ ) can contribute to preventing further bone mineral loss $(\mathrm{AGO}++)$. Oestrogen therapy is not recommended, including hormone receptor-negative carcinoma (LoE 5-D, AGO-).

\section{Targeted Treatment}

Treatment with so-called 'targeted drugs' is granted a high significance in the future therapy of breast cancer. For lapatinib, a molecule which specifically inhibits the tyrosine kinase of epidermal growth factor receptor (EGFR) and HER2, data are available in metastatic breast cancer (fig. 6). Patients pretreated with anthracyclines, taxanes, and trastuzumab, benefit from a combination of lapatinib and capecitabine (LoE 1b-B, $\mathrm{AGO}+$ ). Therapy with trastuzumab and capecitabine is probably not sufficiently effective (LoE $2 \mathrm{~b}-\mathrm{B}, \mathrm{AGO}+/-$ ). There is insufficient experience for first-line therapy with lapatinib and paclitaxel in trastuzumab-naive patients ( $\mathrm{LoE} 2 \mathrm{~b}-\mathrm{B}, \mathrm{AGO}+/-$ ). When resistant to radiotherapy, lapatinib can be helpful in combination with capecitabine for the treatment of brain metastases (LoE 2b-B, AGO+). Also, in the meantime, data have been published on bevacizumab, a monoclonal, human- 
ised antibody against the angiogenetic vascular endothelial growth factor (VEGF) (fig. 7). In first-line therapy, the combination of paclitaxel and bevacizumab increases the rate of remission and extends the progression-free interval (LoE 1b-B,
$\mathrm{AGO}+$ ). Administering additional bevacizumab in second-line therapy (LoE 1b-B, AGO-) or in the combination with capecitabine (LoE 2b $\mathrm{b}^{\mathrm{a}} \mathrm{B}$, AGO-) was not convincing.

\section{References}

1 www.ago-online.de.

2 Goldhirsch A, Wood WC, Gelber RD, Coates AS, Thürlimann B, Senn HJ; 10th St. Gallen conference: Progress and promise: highlights of the international expert consensus on the primary therapy of early breast cancer 2007. Ann Oncol 2007;18:113344.

3 Harris L, Fritsche H, Mennel R, Norton L, Ravdin P, Taube S, Somerfield MR, Hayes DF, Bast RC Jr; American Society of Clinical Oncology: American Society of Clinical Oncology 2007 update of recommendations for the use of tumor markers in breast cancer. J Clin Oncol 2007;25:5287-312.

4 NCCN Clinical Practice Guidelines in Oncology. Breast Cancer. V.I.2008; www.nccn.org.

5 Oxford Centre for Evidence based Medicine: Levels of Evidence, May 2001. www.cebm.net/levels of_evidence.asp, Oxford_CEBM_Levels_5[1].rtf.
6 Aktuelle Empfehlungen zur Therapie Primäre und Fortgeschrittener Mammakarzinome, Hrsg. Kommission Mamma vertreten durch Prof. Thomssen. München, Zuckschwerdt , 2007.

7 www.krebsgesellschaft.de.

8 www.adjuvantonline.com.

$\checkmark$ Schroth W, Antoniadou L, Fritz P, Schwab M, Muerdter T, Zanger UM, Simon W, Eichelbaum M, Brauch H: Breast cancer treatment outcome with adjuvant tamoxifen relative to patient CYP2D6 and CYP2C19 genotypes. J Clin Oncol 2007;25: 5187-93.

10 Arimidex, Tamoxifen, Alone or in Combination (ATAC) Trialists' Group, Forbes JF, Cuzick J, Buzdar A, Howell A, Tobias JS, Baum M: Effect of anastrozole and tamoxifen as adjuvant treatment for early-stage breast cancer: 100-month analysis of the ATAC trial. Lancet Oncol 2008:9:45-53.
11 Coates AS, Keshaviah A, Thürlimann B, Mouridsen H, Mauriac L, Forbes JF, Paridaens R, CastiglioneGertsch M, Gelber RD, Colleoni M, Láng I, Del Mastro L, Smith I, Chirgwin J, Nogaret JM, Pienkowski T, Wardley A, Jakobsen EH, Price KN, Goldhirsch A: Five years of letrozole compared with tamoxifen as initial adjuvant therapy for postmenopausal women with endocrine-responsive early breast cancer: update of study BIG 1-98. J Clin Oncol 2007;25:486-92.

13 Cordeiro PG, McCarthy CM: A single surgeon's 12year experience with tissue expander/implant reconstruction: part I. A prospective analysis of early complications. Part II. An analysis of long-term complications, aesthetic outcomes, and patients satisfaction. Plast Reconstr Surg 2006;118:825-39. 